\title{
Intervenção musical para acompanhantes de crianças no pós-operatório: percepções e
} sentimentos

\section{Musical intervention for companions of children in the post-operative period: perceptions and feelings}

\section{Intervención musical para acompañantes de niños en el postoperatorio: percepciones y sentimientos}

\author{
Recebido: $29 / 06 / 2020$ \\ Aprovado: 27/11/2020 \\ Publicado: 14/04/2021
}

\section{Raquel de Queiroz Matos ${ }^{1}$ Clara Martins de Oliveira ${ }^{2}$ Aline Cristine Candeia de Lira ${ }^{3}$ Mariana André Honorato Franzoi4}

Este estudo teve como objetivo descrever percepções e sentimentos vivenciados por acompanhantes pediátricos durante o período de hospitalização e ao serem submetidos à audição musical no pós-operatório da criança. Trata-se de pesquisa descritiva, de abordagem qualitativa, realizada com 27 acompanhantes de crianças hospitalizadas em uma clínica cirúrgica pediátrica. Os participantes foram submetidos à audição de música instrumental relaxante por quinze minutos. Os dados foram coletados no período de dezembro de 2017 a março de 2018, por meio de entrevista semiestruturada, e submetidos à análise de conteúdo temática. Evidenciaram-se duas categorias temáticas representativas das percepções e sentimentos vivenciados pelos participantes: "O processo de hospitalização pós-cirúrgico da criança para o acompanhante" e "Fá Lá Mi: música na expressão de sentimentos", sendo esta subdividida em três outras subcategorias: Música na harmonização dos sentimentos; A evocação de imagens a partir da música; e, Recomendações para o uso da intervenção musical. A audição musical propiciou uma vivência positiva e também bem-estar emocional aos acompanhantes pediátricos no período pós-operatório.

Descritores: Música; Emoções; Família; Cuidados de enfermagem; Período pós-operatório.

This study aimed to describe perceptions and feelings experienced by companions of children during the hospitalization period and when they were submitted to musical hearing in the child's post-operative period. This is a descriptive research, with a qualitative approach, carried out with 27 companions of children hospitalized in a pediatric surgical clinic. The participants heard relaxing instrumental music for fifteen minutes. Data were collected from December 2017 to March 2018, through semi-structured interviews, and subjected to thematic content analysis. Two thematic categories representing the perceptions and feelings experienced by the participants were created: "The child's post-surgical hospitalization process for the companion" and "F-A-E: music in the expression of feelings", which is subdivided into three other subcategories: Music in the harmonization of feelings; The evocation of images from music; and Recommendations for the use of musical intervention. Musical hearing provided a positive experience and also emotional well-being for companions of children in the post-operative period.

Descriptors: Music; Emotions; Family; Nursing care; Postoperative period.

Este estudio tiene como objetivo describir las percepciones y los sentimientos vividos por los acompañantes de los niños durante el período de hospitalización y al ser sometidos a la escucha de música en el postoperatorio del niño. Se trata de una investigación descriptiva, de enfoque cualitativo, realizada con 27 acompañantes de niños hospitalizados en una clínica quirúrgica pediátrica. Los participantes se sometieron a una escucha de música instrumental relajante durante quince minutos. Los datos se recogieron en el periodo comprendido entre diciembre de 2017 y marzo de 2018, mediante entrevistas semiestructuradas, y se sometieron a un análisis de contenido temático. Se evidenciaron dos categorías temáticas que representan las percepciones y los sentimientos experimentados por los participantes: "El proceso de hospitalización postquirúrgica del niño para el acompañante" y "Fa La Mi: la música en la expresión de los sentimientos", que se subdivide en otras tres subcategorías: La música en la armonización de los sentimientos; La evocación de imágenes a través de la música; y Recomendaciones para el uso de la intervención musical. La escucha musical proporcionó una experiencia positiva y también bienestar emocional a los acompañantes pediátricos en el postoperatorio

Descriptores: Música; Emociones; Familia; Atención de enfermería; Periodo posoperatorio.

1. Enfermeira. Especializanda em Enfermagem em Obstetrícia na modalidade em Residência Uniprofissional pela Secretaria de Estado de Saúde do Distrito Federal, Brasília, DF, Brasil. ORCID: 0000-0002-3341-5523 E-mail: raquelqmatos@gmail.com

2. Enfermeira. Especializanda em Oncologia pelo Instituto de Gestão Estratégica de Saúde do Distrito Federal, na modalidade Residência Multiprofissional, Brasília, DF, Brasil. ORCID: 0000-0001-6408-0618 E-mail: claramartins0514@gmail.com

3. Enfermeira. Especialista em Enfermagem Obstétrica. Enfermeira da Secretaria de Estado de Saúde do Distrito Federal, Brasília, DF. ORCID: 0000-0002-6251-7270 E-mail: candeiaaline@gmail.com

4. Enfermeira. Especialista em Musicoterapia. Especialista em Enfermagem Pediátrica e Neonatologia. Especialista em Linhas de Cuidado em Enfermagem. Mestre e Doutora em Enfermagem. Professora Assistente do curso de graduação em Enfermagem da Universidade de Brasília (UnB), Brasília, DF, Brasil. ORCID: 0000-0002-6877-4753 E-mail: marifranzoiunb@gmail.com 


\section{INTRODUÇÃO}

$\mathbf{0}$

evento cirúrgico no contexto pediátrico geralmente desencadeia preocupação, ansiedade, tristeza, tensão, angústia e medo para a criança e acompanhantes. Frente a isso, deve-se atentar para uma abordagem adequada de cuidado ampliado e centrado na criança e na família, principalmente no acompanhante da criança, pois a maneira com este enfrenta e percebe o processo de hospitalização afeta e influencia diretamente o comportamento e o estado de ansiedade da criança ${ }^{1}$.

0 enfermeiro deve manter-se atento aos sinais de instabilidade emocional e estresse para empregar abordagens que propiciem bem-estar à criança, mas que também minimizem o sofrimento de familiares decorrente do evento cirúrgico ${ }^{2}$.

Ao considerar um plano de cuidado integral e holístico para além do cuidado tradicional estipulado pelas instituições de saúde, a audição musical destaca-se como uma estratégia alternativa para auxiliar no enfrentamento da experiência hospitalar e torná-la menos desagradável e traumática ${ }^{3}$.

A audição musical é um intervenção terapêutica eficiente e imediata que está inserida no Nursing Intervention Classification (NIC) como estratégia de cuidado para diversos Diagnósticos de Enfermagem da North American Diagnostic Association (NANDA), a exemplo do diagnóstico de ansiedade ${ }^{4,5}$, uma vez que a música tem a capacidade de evocar respostas emocionais de calma e induzir o ouvinte a estados de relaxamento ${ }^{6}$.

Em diferentes cenários de cuidado, a música contribui para promover conforto, favorecer a comunicação, promover a socialização, reduzir dores físicas e mentais, além de modular padrões fisiológicos e secreção hormonal7 ${ }^{7}$, com a vantagem de ser uma intervenção de baixo custo, de fácil acesso e não-invasiva ${ }^{8}$.

Considerando esse contexto, delineou-se a seguinte questão de pesquisa: Quais as percepções e sentimentos vivenciados por acompanhantes de crianças durante a hospitalização pós-operatória? E se foram submetidos à audição musical, o que sentirão?

Assim, este estudo teve como objetivo descrever percepções e sentimentos vivenciados por acompanhantes pediátricos durante o período de hospitalização e ao serem submetidos à audição musical no pós-operatório da criança.

\section{MÉTODO}

Trata-se de um estudo descritivo, de abordagem qualitativa, realizado na clínica cirúrgica pediátrica de um hospital da rede pública de saúde de referência na assistência a crianças acometidas por afecções cirúrgicas de todo o Distrito Federal e entorno.

A investigação qualitativa em saúde foca-se nas pessoas e em suas vivências pessoais, centrando-se na busca de significados na medida que fenômenos, manifestações, ocorrências, eventos e sentimentos que moldam as vivências humanas ${ }^{9}$. Conhecer os significados desses fenômenos permite aprofundar a compreensão de emoções e sentimentos de famílias de crianças no pós-operatório e, uma vez que a saúde é das, para e pelas pessoas, uma ausculta das subjetividades propicia desvelar conhecimentos e respostas apropriadas a cada sujeito 9 .

A população-alvo abrangeu acompanhantes de crianças no contexto de internação hospitalar, sendo a amostragem não probabilística, por critério de acessibilidade.

Elegeu-se como critério de inclusão ser acompanhante de crianças submetidas a cirurgias eletivas ou de urgência e ter idade igual ou superior a 18 anos. Participantes com déficits/problemas auditivos ou cognitivos auto-referidos, além daqueles que interromperam a intervenção musical antes do tempo estipulado foram excluídos.

A amostra foi composta por acompanhantes de crianças em pós-operatório e definida pela saturação teórica a saber, quando nenhum elemento novo é desvelado das entrevistas e informações adicionais já não alteram a compreensão do fenômeno em estudo ${ }^{10}$. 
A coleta de dados foi realizada entre dezembro de 2017 e março de 2018. Os participantes da pesquisa foram submetidos à audição de músicas relaxantes como "Let it Be" dos Beatles, "Clube da Esquina" de Milton Nascimento, ambas interpretadas por André Mehmari em modalidade instrumental, e "Concerto para piano No 5 em Mi Bemol Maior, Op. 73" de Ludwig van Beethoven interpretada por City of London Sinfonia, Cristina Ortiz \& Richard Hickox. As músicas foram selecionadas conforme as recomendações estabelecidas pelo Instituto Joanna Briggs $^{11}$, e executadas por meio de aparelho MP3 Player e fones de ouvidos durante 15 minutos no período pós-operatório.

Após a audição das músicas, foi realizada entrevista semiestruturada para investigar a percepção dos acompanhantes a respeito da hospitalização da criança, bem como sobre a intervenção utilizada e os sentimentos vivenciados durante a experiência musical. Para isso, adotaram-se as seguintes perguntas norteadoras: Como você tem se sentido esses dias no hospital? Por quê (devido a quê)? Como você se sentiu enquanto ouvia as músicas? E como você se sente agora, depois de ter ouvido as músicas? O que você pensa/acha sobre utilizar a música como uma estratégia para alívio de sentimentos negativos? Além disso, caracterizaram-se os participantes em relação ao gênero, grau de parentesco com a criança e perfil sonoro musical.

As entrevistas foram gravadas em dispositivo de áudio digital com média de duração de 4 minutos. A gravação foi realizada para facilitar a obtenção de diálogo e evitar a perda de dados significativos, e posteriormente, foram transcritas na íntegra, sendo garantido o anonimato dos participantes durante todas as etapas do processo da pesquisa. Para a apresentação das falas transcritas dos participantes, enumerou-se pelo termo "acompanhante" seguido de notas musicais.

Os dados foram submetidos à análise de conteúdo temática na proposição de Bardin para compreender o sentido do conteúdo emitido a partir da estruturação de três etapas: préanálise, exploração do material e categorização dos temas emergentes ${ }^{12}$.

Esta pesquisa foi aprovada pelo Comitê de Ética em Pesquisa (CEP) da Fundação de Ensino e Pesquisa em Ciências da Saúde, sob número de parecer 2.051.171 e CAAE: 67099617.2.0000.5553. A formalização da participação dos sujeitos foi realizada por meio da leitura e assinatura do Termo de Consentimento Livre e Esclarecido de forma a assegurar e respeitar todos os direitos estabelecidos na Resolução n. 466/2012 do Conselho Nacional de Saúde.

\section{RESULTADOS}

A amostra foi constituída por 27 participantes, majoritariamente do sexo feminino, com idades variando entre 20 e 70 anos. Em relação ao grau de parentesco, a maioria eram mães, porém algumas crianças foram acompanhadas por avós, tios(as), madrastas, irmãos ou pais.

Muitos relataram o hábito de ouvir música em seu cotidiano com preferência de estilo sertanejo e gospel, sendo que um número expressivo de participantes não tocava instrumentos e/ou nunca estudou música.

A partir da análise de conteúdo das entrevistas realizadas foram evidenciadas duas categorias temáticas representativas das percepções e sentimentos vivenciados, a saber: $O$ processo de hospitalização pós-cirúrgico da criança para o acompanhante; e Fá Lá Mi: música na expressão de sentimentos. Esta segunda categoria foi subdividida em três subcategorias intituladas: Música na harmonização dos sentimentos; A evocação de imagens a partir da música; e Recomendações para o uso da intervenção musical.

\section{1) 0 processo de hospitalização pós-cirúrgico da criança para o acompanhante}

0 processo de adoecimento da criança pode desencadear diversos sentimentos em quem acompanha e vivencia de perto a hospitalização, em especial, medo, tensão, nervosismo e tristeza. 
A preocupação com a saúde da criança, com a recuperação pós-operatória e com a adaptação da rotina após a alta hospitalar foram relacionadas a sentimentos de tensão. Muitas mães que acompanhavam seus filhos na hospitalização manifestaram preocupação com seus outros filhos que estavam em casa e dependiam dos cuidados de terceiros. Outra preocupação pertinente foi a dificuldade em deixar o hospital ou retornar ao trabalho e realizar cuidados à criança:

E acho que assim preocupação, né, porque eu tenho outra filha. Fico pensando lá e o outro aqui. [...] Mas no momento eu acho que a prioridade é dele. O pensamento é nele. (Acompanhante Dó maior)

Sim, tô muito preocupada; até porque não vou nem trabalhar pra ficar cuidando dela porque eu tô com medo de deixar ela com outra pessoa e eu não sei como que vai ser os cuidados, né. (Acompanhante Si bemol)

A ansiedade pela volta para casa, além de sentimentos de tristeza e cansaço foram relatados à forte carga emocional:

Muito cansada e ansiosa [...] preocupada, né? Com o pós-operatório dele. Ele está tendo algumas complicações, é mais por isso. (Acompanhante Lá menor)

Essa carga emocional pode estar relacionada à empatia e à piedade sentida em prol da criança, conforme ilustrado no trecho abaixo:

Ah, porque é um pedaço meu e quando fica falando que tá sentindo dor... aquilo me acaba. (Acompanhante Fá sustenido)

Alguns acompanhantes, por outro lado, relataram sentimentos de tranquilidade relacionados principalmente ao quadro clínico momentâneo da criança e à crença de que o período de potenciais complicações, o procedimento cirúrgico em si, já havia sido superado: Ah, tranquila. Porque ele tá bem, ele não tá dando nenhum sinal assim, né, de algum tipo de infecção que é o que preocupa na recuperação [...] mas graças a Deus ele tá bem então eu tô tranquila. Na verdade, a gente vai indo de acordo com o quadro dele, né. Quando ele tá bem você vai ficando tranquila e se acontece alguma coisa você começa a ter preocupação. (Acompanhante Mi bemol)

Tô tranquila. Só sei que tô tranquila. Depois da cirurgia fiquei muito tranquila. Porque saiu do perigo. (Acompanhante Ré maior)

Quanto às alegações de tranquilidade, foi possível perceber relatos de gratidão pelo procedimento cirúrgico realizado e pelo bom atendimento prestado pela equipe de saúde:

Tem muitas pessoas, os médicos dão muita atenção. Os enfermeiros, né. Tem assim muita gente em volta que tá ajudando muito. Total assistência. [...] Isso aí dá uma força muito grande. (Acompanhante Sol maior)

0 sentimento e a sensação de segurança apareceram em dicotomia quando alguns acompanhantes mencionaram sentir-se seguros durante o período de internação por estarem sob o olhar e cuidados da equipe de saúde, enquanto outros acompanhantes descreveram estarem ansiosos pela volta para casa para que pudessem cuidar da criança com mais segurança e conforto:

Porque enquanto tá aqui no hospital a gente sabe que tá tudo bem, né. E quando a gente chega em casa é diferente. (Acompanhante Ré menor)

Acho que a ansiedade mesmo de sair daqui, levar ele pra casa. Lá a gente cuida melhor do que aqui. Aqui tá certo que tem os médicos e tudo né, mas nunca é que nem a casa da gente. (Acompanhante Lá maior)

\section{2) Fá Lá Mi: música na expressão de sentimentos}

Subdividiu-se essa categoria em três subcategorias que abordam os sentimentos aflorados durante e após a intervenção, os cenários imaginados pelos acompanhantes enquanto ouviam as músicas e as sugestões e recomendações para futuras aplicações da audição musical no contexto hospitalar.

\section{- Música na harmonização dos sentimentos}

Os acompanhantes referiram sentir-se tranquilos, relaxados, calmos e sonolentos durante e após a intervenção musical. Durante a realização da intervenção, foi possível avaliar como os acompanhantes se portavam e grande parte deles aparentava sono ou estavam propensos a dormir, permanecendo de olhos fechados durante a intervenção, reclinados na poltrona e sem interagirem com as pessoas à sua volta.

Quase dormi [risos]. Com sono. É uma calmaria, eu amei, gostei. (Acompanhante Dó menor) Tranquila. Sono. Eu até relaxei um pouquinho. (Acompanhante Lá menor) 
Os participantes atribuíram esses sentimentos de calma e relaxamento ao estilo de música escolhido, o qual foi aprovado por todos, mesmo por aqueles que não tinham o hábito de ouvir música instrumental no cotidiano:

Relaxa assim por dentro, sei lá, uma coisa boa. (Acompanhante Fá menor)

Ah, instrumental é uma música que independente do que você gosta, agrada, né? (Acompanhante Ré sustenido com terça)

Ótima, eu gostei. Calma, tranquila, é bom. Acalma a mente, gostei. (Acompanhante Mi bemol)

A internação hospitalar limita a privacidade, o lazer e o conforto do paciente e da família. A distração ocasionada pelos 15 minutos de audição musical foi considerada uma estratégia de alívio ante a tensão e hostilidade que perpassam o ambiente hospitalar:

Então, assim, quando a gente escuta música num ambiente desse que não é tão favorável, veio pra tranquilizar mesmo. (Acompanhante Ré menor)

É válido, né. Realmente é válido. Porque realmente é um ambiente estressante. Muitas vezes quando a gente vem aqui numa emergência a pessoa fica uma pilha de nervos, principalmente mexendo com criança. Então realmente essa coisa de parar pra relaxar é válido. (Acompanhante Si maior)

A música tornou oportuna a sensação de serem transportados para um ambiente calmo ao desviar o foco do estresse e das tensões. Alguns participantes relataram ficar com a "mente vazia", "em branco" em consequência do profundo relaxamento que a audição musical lhes proporcionou:

A música te tira, de certa forma, te tira do ambiente. Um pouco do ambiente que você tá de pressão das coisas, né. Aí você pensa em uma coisa, pensa em outra e quando você tá escutando música você esquece um pouco. (Acompanhante Mi bemol)

A música, ela vem pra acalmar naquele momento que você está tão nervosa, tão tensa que você tá assim, trancada no quarto, ansiosa, esperando por uma resposta. E você tá aqui, não tem nem uma televisão, então acaba que a música vem para tranquilizar, te deixar mais calma e te levar pra outro mundo. (Acompanhante Si menor)

0 apreço pessoal pelas músicas apresentou-se como um fator facilitador, uma vez que os participantes que se sentiram atraídos pelas músicas que lhes eram familiares ou traziam à tona alguma memória estiveram mais abertos e entregues ao momento da audição musical e, a partir disso, evocaram boas sensações e recordações associadas, inclusive, à espiritualidade:

Fiquei pensando no que tava sendo tocado. Gostei. Tem até uma música aí que tocou dos Beatles, né? Let It Be, né? Bacana. (Acompanhante Mi bemol)

Toda sexta-feira eu vou pra comunhão. Essa música é o tipo da música de lá que eles colocam pra gente se acalmar, ficar em oração. (Acompanhante Sol sustenido com terça)

De modo geral, a audição musical trouxe um quadro de melhora emocional dos participantes em comparação ao estado psíquico e emocional de preocupação, cansaço e ansiedade que estavam presentes antes da audição musical:

Me sinto melhor, me sinto bem. A música ela relaxa, ela tranquiliza. (Acompanhante Dó maior com sétima)

\section{- A evocação de imagens a partir da música}

A intervenção musical trouxe à tona imagens e memórias com a visualização mental de cenários musicais, como orquestras, shows, cultos e missas:

Imaginei uma orquestra. E eu ficava me imaginando tocar assim. (Acompanhante Dó maior com sétima)

Alguns entrevistados relataram que a audição evocou todo o processo que vivenciaram durante o transoperatório da criança:

Do começo. Assim, da trajetória dela, né. Eu indo pro hospital de madrugada. Vai passando uma cena assim na cabeça da gente. (Acompanhante Ré sustenido com terça)

Em outros, a audição musical avivou a esperança da volta para casa, além da recordação de familiares que estavam distantes devido ao processo de internação hospitalar:

Eu só fico vivendo essa situação que ela passou, quando ela operou até o dia de hoje. Eu tô com muita vontade de ir pra casa. Fiquei pensando nisso tudo. Já tem mais de dez dias. (Acompanhante Sol maior)

Me lembrei muito dos meus filhos. Lembrei demais deles. Tenho seis. Lembrei deles tudinho. Passou só eles na minha cabeça. (Acompanhante Si maior)

\section{- Recomendações para o uso da intervenção musical}

0 uso da intervenção foi descrito de forma unânime pelos acompanhantes como uma forma importante de auxiliar o momento angustiante que estavam vivenciando: 
Muito bom, muito bom. Porque pode não aliviar cem por cento, mas pelo menos uma boa parte ajuda. [...] É muito bom, eu recomendo. (Acompanhante Sol maior)

Em relação à implementação da intervenção musical no contexto hospitalar, elencaramse algumas sugestões e recomendações para seu uso, sendo uma delas a necessidade de um ambiente mais calmo, sem distrações ao redor:

Eu acho ótimo. Ajuda desde que não tenha ninguém conversando com a pessoa porque dá pra concentrar mais, né? (Acompanhante Fá maior)

Alguns acompanhantes sugeriram um tempo de intervenção menor, pois começaram a se sentir impacientes ao final dos 15 minutos. Em contrapartida, outros opinaram por um tempo mais longo para alcançarem um nível de maior relaxamento:

Talvez o limite de tempo um pouco menor porque tem gente que não aprecia a música, esse tipo de música. Aí talvez vá ficando... ai, cansativo, né. Mas, com um tempo menor acho que dá um efeito terapêutico bom. (Acompanhante Dó menor)

É pouco tempo, mas eu acredito que se eu passasse o dia todo aqui ouvindo, eu ficaria bem mais relaxada. (Acompanhante Lá menor com sétima)

Outros questionaram sobre a adoção de música instrumental para aqueles que não se interessam por este estilo musical:

Dependendo do tipo de música cada um tem uma reação diferente, né? (Acompanhante Dó sustenido com sétima)

Uma sugestão pertinente foi a necessidade de alguém estar presente para cuidar da criança durante a intervenção para que pudessem estar focados somente na audição musical: Eu não tava, assim, preocupado com a minha filha. Como a minha cunhada já estava aqui aí eu não preciso estar com a atenção nela, né. Aí eu consigo focar mais na música e me tranquilizar através disso. (Acompanhante Lá maior com quinta)

Sugeriu-se a possibilidade da audição musical ser realizada de forma rotineira por meio de som ambiente nos corredores hospitalares, e não somente por meio do fone de ouvido:

Acho bacana. Eu só acho que não deveria ser assim numa situação de 'ah, 15 minutinhos de música', mas acho que deveria ser alguma coisa natural. Assim, um som desse no corredor do hospital, por exemplo. De forma diária, como se fosse um hábito. É, não seria dentro da sala, mas seria no corredor, né. (Acompanhante Ré sustenido com terça)

Outra proposta ainda de tornar a experiência da cirurgia pediátrica menos traumática seria realizar a audição musical durante o período intraoperatório, pois, trata-se de um dos momentos de maior angústia, sofrimento, incertezas e ansiedade vividos pelo acompanhante: Ah, eu acho que vai ser excelente. Vai, vai ser excelente. Porque a gente passa muito tempo aqui sozinha. Não sozinha, tem gente no quarto, mas assim sem o apoio da família aqui do lado. Principalmente lá na... eu nunca me senti tão sozinha igual eu fiquei ali na sala de espera esperando do centro cirúrgico. Eu fiquei muito triste ali, não tendo ninguém. Muito ansiosa. Ai, tudo que podia acontecer eu imaginei. (Acompanhante Mi menor com sétima)

\section{DISCUSSÃO}

A hospitalização acarreta em restrições e desorganização de atividades rotineiras do paciente e família, especialmente para a mulher que acumula papéis de mãe, trabalhadora e cuidadora. Gênero predominante nesta pesquisa, a mulher é vista como principal cuidadora da família, independente de seus outros afazeres. Ao assumir esse papel de cuidado intenso à criança hospitalizada e muitas vezes de dedicação exclusiva, a mulher deve delegar a partilha dos cuidados a outros membros da família para que mudanças drásticas, a exemplo do abandono de suas atividades diárias e saída do emprego, não se tornem uma realidade ${ }^{13}$.

A família da criança em situação cirúrgica é um elemento valioso no cuidado. Ao garantir que o acompanhante pediátrico seja inserido no cuidado de forma participativa, é possível que a experiência da hospitalização seja menos traumática, porém é imprescindível que a família esteja emocionalmente fortalecida para acalmar e lidar com as angústias da criança e oferecer suporte a ela ${ }^{14}$.

Quando encontram-se fragilizados emocionalmente, entregues ao estresse, tristeza e preocupações, a capacidade dos familiares em demonstrar apoio, carinho e companhia para o paciente pediátrico se torna um fardo extremamente pesado ${ }^{15}$.

Na enfermagem, a música vem sendo utilizada como uma prática de cuidado humanizado à saúde para incentivar estado de relaxamento, melhora da qualidade de vida, auxílio na 
superação dos sentimentos de sofrimento e melhor capacidade para enfrentamento da situação de saúde-doença ${ }^{16}$.

A música apresentou-se como estratégia de redução da tensão e ansiedade ocasionadas pelo estresse da internação da criança. Além de ser um recurso de alívio da dor e de melhoria da qualidade do padrão de sono, a música relaxante pode incentivar a liberação de substâncias cerebrais que afetam de forma positiva o humor de quem a escuta de forma a contribuir até mesmo para o conforto espiritual ${ }^{17}$.

Os relatos dos acompanhantes revelaram a música como recurso potencial de apoio psicoemocional e espiritual que pode auxiliá-los no enfrentamento do processo de hospitalização ao mudar o foco de um evento estressante para uma vivência musical agradável e prazerosa.

Os dados corroboram com diversos outros estudos que evidenciaram o benefícios da música para cuidadores e acompanhantes ${ }^{18,19}$. Em estudo realizado na internação pediátrica de um hospital na região sul do país, observou-se que a música contribuiu para promover descontração, mudança de humor e relaxamento às crianças e famílias, amenizando a angústia, os medos e inseguranças relacionadas ao tratamento da doença ${ }^{18}$. Em outro estudo a música auxiliou pacientes e familiares na expressão de pensamentos, sentimentos e conflitos vivenciados durante o tratamento oncológico em ambiente hospitalar ${ }^{19}$.

Cuidadores relataram menores níveis de ansiedade, estresse e melhora do humor ao ouvirem músicas de sua preferên cia $^{20}$, e mães que acompanharam seus filhos em internação hospitalar apresentaram redução do estado de ansiedade após a audição de canto gregoriano ${ }^{21}$.

Os participantes também relataram a evocação de imagens e memórias durante a escuta musical, uma transformação do estímulo auditivo em experiência visual realizada pelo cérebro. Esse dado corrobora os dados de pesquisa realizada com mulheres com dor musculoesquelética que observou que a mente humana se comporta de maneira a influenciar o fluxo de imagens mentais oriundo da simbolização dos sentimentos evocados através da audição musical tal que materiais sonoros mais estruturados e definidos, a exemplo das músicas clássicas, apresentam maior potencial para evocar imagens ${ }^{22}$.

Ao realizar a seleção musical, deve-se levar em consideração o estilo musical, sendo a música clássica considerada um estilo apropriado para obtenção de efeito relaxante pelos sons de baixa intensidade, andamento lento e com pouca atividade rítmica, porém deve-se observar a preferência musical do indivíduo, como sugerido por alguns participantes, afinal há evidências de que ao ouvir músicas que lhe agradem, o nível de ansiedade do ouvinte pode diminuir consideravelmente, independentemente do andamento e ritmo musical ${ }^{23}$.

Em relação à duração ideal da intervenção musical, houve divergência nas opiniões dos participantes. 0 tempo de intervenção pode variar em um intervalo abrangente de 5 minutos a 4 horas, sendo a duração média de 15 a 30 minutos, porém são necessários novos estudos, uma vez que ainda não há evidências que determinem e especifiquem uma duração precisa ${ }^{11}$.

Diante de poucas pesquisas que investigam os benefícios da música em acompanhantes pediátricos, a maioria com enfoque no período pré-operatório ${ }^{24}$, este estudo destaca-se ao desvelar as vantagens do uso da intervenção musical no pós-operatório. Trata-se de um momento, por vezes, considerado impassível e seguro para alguns, porém requer cuidados e atenção assim como no período pré-operatório, pois é marcado por muitas preocupações, cansaço e tensões no cuidado à criança.

\section{CONCLUSÃo}

0 período de hospitalização foi marcado por medo, cansaço e muita preocupação da família em relação à saúde da criança e receios com os cuidados pós-operatório e com a adaptação à nova rotina após a alta hospitalar.

A audição musical apresentou-se como uma intervenção estratégica no pós-operatório para propiciar o bem-estar aos acompanhantes e tê-los como aliados no cuidado à criança, uma 
vez que relataram estado de relaxamento, tranquilidade e calmaria durante e após a experiência musical.

Dentre as limitações dessa pesquisa, destaca-se o local de realização da intervenção musical, a saber, quartos de enfermaria coletiva, local movimentado onde profissionais circulam e constantemente realizam procedimentos, além de transitarem outros acompanhantes e crianças. 0 ideal para a promoção de maior grau de relaxamento dos acompanhantes seria um local mais reservado e intimista.

Sugere-se para futuras pesquisas que a intervenção seja realizada em outros períodos operatórios, com destaque para o transoperatório, como sugerido pelos próprios participantes desta pesquisa. É necessário aprofundar investigação no que tange à duração da intervenção, maior ou menor aos 15 minutos utilizados nesta pesquisa, bem como se há diferenças entre a audição musical individual e a audição de música ambiente.

Conclui-se que audição musical apresenta-se como uma potencial intervenção de enfermagem para promover o cuidado humanizado centrado na criança e na família, auxiliando-os a vivenciarem o período pós-operatório de forma mais agradável e menos traumática.

\section{REFERÊNCIAS}

1. Franzoi MAH, Martins G. Ansiedade de crianças em situação cirúrgica e percepções emocionais reportadas por seus acompanhantes no pré-operatório: um estudo exploratório. REME Rev Min Enferm. [Internet]. 2016 [citado em 21 out 2019]; 20:e984. Disponível em: http://www.reme.org.br/artigo/detalhes/1120

2. Firmeza MA, Rodrigues AB, Melo GAA, Aguiar MIF, Cunha GH, Oliveira PP, et al. Uso da música no controle da ansiedade em ambulatório de cabeça e pescoço: ensaio clínico randomizado. Rev Esc Enferm USP [Internet]. 2017 [citado em 21 out 2019]; 51:e03201. DOI: https://doi.org/10.1590/s1980-220x2016030503201

3. Franzoi MAH, Goulart CB, Lara EO, Martins G. Music listening for anxiety relief in children in the preoperative period: a randomized clinical trial. Rev Latinoam Enferm. [Internet]. 2016 [citado em 21 out 2019]; 24:e2841. DOI: https://doi.org/10.1590/1518-8345.1121.2841

4. Campos LF, Nakasu MV. Efeitos da utilização da música no ambiente hospitalar: revisão sistemática. Rev Sonora [Internet]. 2016 [citado em 26 out 2019]; 6(11):1-19. Disponível em: http://www.publionline.iar.unicamp.br/index.php/sonora/article/view/686/659

5. Cardoso AVM, Sousa AAM, Silva PLN, Carvalho, HLA, Alves, ED, Aguiar Filho W. Cuidado com arte: a promoção da saúde por meio da música. Rev Univ Vale do Rio Verde [Internet]. 2016 [citado em 26 out 2019]; 14(1):714-35. Disponível em: http://periodicos.unincor.br/index.php/revistaunincor/article/view/2531/pdf_472

6. Nunes-Silva M, Valadares ACD, Rosa GT, Lopes LCM, Marra CAS. Avaliação de músicas compostas para indução de relaxamento e de seus efeitos psicológicos. Psicol Ciênc Prof [Internet]. 2016 [citado em 20 nov 2019]; 36(3):709-25. DOI: https://doi.org/10.1590/19823703001672014

7. Araújo TC, Pereira A, Sampaio ES, Araújo MSS. Uso da música nos diversos cenários do cuidado: revisão integrativa. Rev Baiana Enferm. [Internet]. 2014 [citado em 20 nov 2019]; 28(1):96-106. Disponível

em: https://portalseer.ufba.br/index.php/enfermagem/article/view/6967

8. Hole J, Hirsch M, Ball E, Meads C. Music as an aid for postoperative recovery in adults: a systematic review and meta-analysis. Lancet [Internet]. 2015 [citado em 04 ago 2020]; 386(10004):1659-71. DOI: https://doi.org/10.1016/s0140-6736(15)60169-6

9. Ribeiro J, Souza DN, Costa AP. Investigação qualitativa na área da saúde: por quê? Ciênc Saúde Colet. [Internet]. 2016 [citado em 25 jun 2020]; 21(8):2324. DOI: https://doi.org/10.1590/1413-81232015218.15612016 
10. Nascimento LCN, Souza TV, Oliveira ICS, Moraes JRMM, Aguiar RCB, Silva LF. Saturação teórica em pesquisa qualitativa: relato de experiência na entrevista com escolares. Rev Bras Enferm. [Internet]. 2018 [citado em 25 jun 2020]; 71(1):243-8. DOI: https://doi.org/10.1590/0034-7167-2016-0616

11. Joanna Briggs Institute. The Joanna Briggs Institute Best Practice Information Sheet: music as an intervention in hospitals. Nurs Health Sci. [Internet]. 2011 [citado em 20 out 2019]; 13(1):99-102. DOI: https://doi.org/10.1111/j.1442-2018.2011.00583.x

12. Bardin L. Análise de conteúdo. 1ed. reimpr. Lisboa: Edições 70; 2016. 282p.

13. Neves ET, Cabral IE, Silveira A. Family network of children with special health needs: implications for Nursing. Rev Latinoam Enferm. [Internet]. 2013 [citado em 20 nov 2019]; 21(2):562-70. DOI: https://doi.org/10.1590/S0104-11692013000200013

14. Albuquerque DB, Morais RCM, Macedo IF, Vieira RFC, Souza TV. A família no cenário hospitalar pediátrico a partir da década de 1990: uma revisão integrativa. Cogitare Enferm. [Internet]. 2013 [citado em 20 nov 2019]; 18(4):789-95. DOI: http://dx.doi.org/10.5380/ce.v18i4.34938

15. Reis LS, Silva EF, Waterkemper R, Lorenzini E, Cecchetto FH. Percepção da equipe de enfermagem sobre humanização em unidade de tratamento intensivo neonatal e pediátrica. Rev Gaúcha Enferm. [Internet]. 2013 [citado em 10 out 2019]; 34(2):118-24. DOI: http://dx.doi.org/10.1590/S1983-14472013000200015

16. Zarghi A, Zali A, Ashrafi F, Moazezi S. Assessment of brain function in music therapy. Amer J Appl Psychol. [Internet]. 2014 [citado em 10 out 2019]; 2(3):66-8. Disponível em: http://pubs.sciepub.com/ajap/2/3/2/ajap-2-3-2.pdf

17. Cruz IM, Souza IRD, Santos MP, Souza AG, Soares JR, Souza LPS, et al. A música como intervenção e cuidados em saúde: revisão integrativa. Rev G\&S [Internet]. 2015 [citado em 20 nov 2019]; 6(1):549-64. Disponível em: http://periodicos.unb.br/index.php/rgs/article/view/13753/9687

18. Silva GH, Piovesan JC. Ambiente hospitalar: uma possibilidade de proporcionar alegria e ludicidade na internação. Vivências [Internet]. 2018 [citado em 04 ago 2020]; 14(26):204-19. Disponível

em:

http://www2.reitoria.uri.br/ vivencias/Numero_026/artigos/pdf/Artigo_17.pdf

19. Martins AM, Balduino TB. Música como recurso terapêutico no hospital oncológico: relato de experiência. Rev Psicol IMED [Internet]. 2020 [citado em 04 ago 2020]; 12(1):148-60. DOI: https://doi.org/10.18256/2175-5027.2020.v12i1.3518

20. Quinn-Lee L, Mowry D. Effects of personalized music on caregivers o folder adults with dementia in the community. WMJ [Internet]. 2019 [citado em 04 ago 2020]; 118(2):80-3. Disponível em: https://wmjonline.org/wp-content/uploads/2019/118/2/80.pdf

21. Almeida AP, Silva MJP. Canto gregoriano: redutor de ansiedade de mães com filhos hospitalizados. Acta Paul Enferm. [Internet]. 2012 [citado em 04 ago 2020]; 25(1):36-42. DOI: http://dx.doi.org/10.1590/S0103-21002012000100007

22. Leão ER, Silva MJP. Música e dor crônica músculoesquelética: o potencial evocativo de imagens mentais. Rev Latinoam Enferm. [Internet]. 2004 [citado em 20 nov 2019]; 12(2):23541. DOI: https://doi.org/10.1590/S0104-11692004000200013

23. Jiang J, Zhou L, Rickson D, Jiang C. The effects of sedative and stimulative music on stress reduction depend on music preference. Art Psychother. [Internet]. 2013 [citado em 20 nov 2019]; 40(2):201-5. DOI: https://doi.org/10.1016/j.aip.2013.02.002

24. Millet CR, Gooding LF. Comparing active and passive distraction-based music therapy interventions on preoperative anxiety in pediatrc patients and theis caregivers. J Music Ther. [Internet]. 2017 [citado em 04 ago 2020]; 13(54):460-78. DOI: https://doi.org/10.1093/jmt/thx014 
Editora Associada: Vania Del Arco Paschoal

\section{CONTRIBUIÇÕES}

Aline Cristine Candeia de Lira e Clara Martins de Oliveira participaram da concepção, coleta e análise dos dados. Mariana André Honorato Franzoi e Raquel de Queiroz Matos contribuíram na concepção, coleta e análise dos dados, redação e revisão.

\section{Como citar este artigo (Vancouver)}

Matos RQ, Oliveira CM, Lira ACC, Franzoi MAH. Intervenção musical para acompanhantes de crianças no pós-operatório: percepções e sentimentos. REFACS [Internet]. 2021 [citado em inserir dia, mês e ano de acesso]; 9(2):383-92. Disponível em: inserir link de acesso. DOI: inserir link do DOI

\section{Como citar este artigo (ABNT)}

MATOS, R. Q.; OLIVEIRA, C. M.; LIRA, A. C. C.; FRANZOI, M. A. H. Intervenção musical para acompanhantes de crianças no pós-operatório: percepções e sentimentos. REFACS, Uberaba, MG, v. 9, n. 2, p. 383-92, 2021. DOI: inserir link do DOI. Disponível em: inserir link de acesso. Acesso em: inserir dia, mês e ano de acesso.

\section{Como citar este artigo (APA)}

Matos, R.Q., Oliveira, C.M., Lira, A.C.C., \& Franzoi, M.A.H. (2021). Intervenção musical para acompanhantes de crianças no pós-operatório: percepções e sentimentos. REFACS, 9(2), 383-92. Recuperado em inserir dia, mês e ano de acesso de inserir link de acesso. DOI: inserir link do DOI. 